\title{
Study on the Disposition of Water in Fly Ash-Based Geopolymers Using ATR-IR
}

\author{
Jian Liu and Yuan Fang \\ School of Civil Engineering, Shenzhen University, China
}

Obada Kayali

School of Engineering and Information Technology, University of New South Wales, Canberra, Australia

\begin{abstract}
This paper addresses the question of whether the main product of low calcium fly ash-based geopolymer is a hydrate, namely, sodium aluminosilicate hydrate (N-A-S-H). The answer to this question is important for understanding geopolymer characteristics. One of these is its fire resistance. In this study, fly ash-based geopolymers were synthesized using the combination of $\mathrm{Na}_{2} \mathrm{CO}_{3}$ and $\mathrm{Ca}(\mathrm{OH})_{2}$. Samples were cured at ambient temperature for 7 days, then placed in the oven at $105^{\circ} \mathrm{C}$ for $24 \mathrm{~h}$, and then calcined at $1050^{\circ} \mathrm{C}$ for $48 \mathrm{~h}$. IR was used to examine the produced geopolymers at each stage so as to further knowledge on the following issues: the possibility of co-existence of calcium aluminosilicate hydrate ( $\mathrm{C}-\mathrm{A}-\mathrm{S}-\mathrm{H})$ and $\mathrm{N}-\mathrm{A}-\mathrm{S}-\mathrm{H}$, the roles of cations as compensator and network modifier as well as the role of water. The results obtained suggest that the primary geopolymerization products, which are potentially good fire-resistant, are unlikely to contain hydrates. Even if there were hydrates, their amount must be very small such that the escaping of water does not compromise the structure's integrity.
\end{abstract}

\section{INTRODUCTION}

Geopolymer is an "environmentally green" material, which has been claimed to excel Portland cement in many aspects, a material that could potentially be the future "cement." It was proposed by Davidovits in the late 1970 s, referring to the amorphous to semi-crystalline three-dimensional silico-aluminate materials activated in a highly alkaline environment (Davidovits, 2008). As the understanding of geopolymers increases, the chemistry behind geopolymerization process gradually unravels. One aspect that has recently been researched is to determine whether geopolymer is a hydrate. Davidovits (2008) has used the term polysialate to describe all geopolymers that have at least one $\mathrm{M}-(\mathrm{Si}-\mathrm{O}-\mathrm{Al})$, that is, $\mathrm{M}$-sialate unit (sialate is an abbreviation for alkali silicon-oxo-aluminate and $M$ stands for metal ions). This term is represented by the empirical formula: $\mathrm{M}_{\mathrm{n}}\left(-\left(\mathrm{SiO}_{2}\right)_{\mathrm{z}}-\mathrm{AlO}_{2}\right)_{\mathrm{n}}, \mathrm{wH}_{2} \mathrm{O}$, in which the water molecule is not considered as an integral part of the geopolymer matrix. To avoid confusion about different terminologies of water throughout this research, the water in geopolymers discussed, will be classified in three categories: free water, physically adsorbed water, and structural water. Free water is the water that is absorbed and held in macro-pores and is beyond the range of the surface forces of the solid phase. The transition temperature, enthalpy, and peaks obtained in DSC curves for the free water are equal to those of pure water as in the case of free water defined in cement chemistry (Nakamura,
Hatakeyama, \& Hatakeyama, 1981; Neville, 2011). The term structural water as used in this research refers to the part of water molecules, which is rigidly bound mainly by hydrogen bonding and constitutes an integral part of the geopolymer matrix in the form of molecular water. Thus, structural water, if any exists in geopolymers, should be rigidly bound and different from adsorbed water. It should constitute an integral part of a geopolymer and the loss of which would causes the decomposition of its structure. From this perspective, it is analogous to the "H" in $\mathrm{C}-\mathrm{S}-\mathrm{H}$, which constitutes an integral part of what is known as C-S-H gel. It is therefore appropriate to note here that the term "gel" has also been used to describe the amorphous and polymeric property of geopolymers.

Contrary to Davidovits' perception about geopolymer not being a hydrate, some researchers since 2005 (Fernández-Jiménez, Palomo, Sobrados, \& Sanz, 2006; Fernández-Jiménez, A., Garcia-Lodeiro, I., \& Palomo, A. 2007; Palomo, Fernández-Jiménez, Kovalchuk, Ordoñez, \& Naranjo, 2007), have claimed that $\mathrm{Na}$ geopolymer is sodium aluminosilicate hydrate (N-A-S-H). The term is "an acronym for sodium aluminosilicate gel forming as the main reaction product in alkali activated fly ash materials," and "terminological analogy to C-S-H gel" as well as "descriptive analogy to actual gel composition (sodium aluminosilicate hydrate, N-A-S-H)" (Fernández-Jiménez \& Palomo, 2009). This term, 
together with K-A-S-H (potassium aluminosilicate hydrate) or similar gels, was introduced by FernándezJiménez and Palomo (2005a). Prior to this, the understanding of geopolymeric product was not based on it being defined as a hydrate, it was considered as an "aluminosilicate" (Alonso \& Palomo, 2001a, 2001b). Nevertheless, in those research papers (Shi, Fernández-Jiménez, \& Palomo, 2011) that considered the main product of geopolymer as a hydrate, the role and deposition of the water, especially the structural water, were not addressed.

In 2009, Fernández-Jiménez and Palomo (2009) claimed that the concept "N-A-S-H" was first introduced in an early paper (Fernández-Jiménez \& Palomo, $2005 b)$ they published in 2005. However, in that very paper (Fernández-Jiménez, Palomo, \& Criado, 2005c), the term N-A-S-H has appeared only once in the conclusion section without explanation of what exactly it stood for. In the rest of the paper (Fernández-Jiménez, Palomo, \& Criado, 2005), the geopolymer product was referred to as "aluminosilicate gel." Also, the role of water was not addressed except for the brief mention of the appearance of stretching and deformation modes of water, which appear in the FTIR spectra at 3500 and $1600 \mathrm{~cm}^{-1}$, respectively. However, these two vibration modes are not exclusive to structural water; free water also exhibits such vibration modes at these two frequencies. This was not clearly discussed in the aforementioned paper. Nevertheless, the concept "N-A-S-H" was widely accepted in the description of geopolymers (White, Provis, Proffen, \& Van Deventer, 2011, 2010). In 2010, Fernández-Jiménez, Pastor, Martin, and Palomo (2010) further explained that part of the water in geopolymers can be considered as zeolite water ${ }^{1}$, and the $\mathrm{Na}^{+}$is in a "hydrated" state filling the gaps of the geopolymer matrix. They based this explanation on the observation that the evaporation of this water does not compromise the stability of the geopolymers when exposed to high temperatures. However, the water in zeolites comprises zeolite water as well as structural water, wherein the loss of structural water leads to the destruction of the zeolite's structure (Castaldi \& Santona, 2005). Furthermore, FernándezJiménez, Palomo, Pastor, and Martin (2008) attribute the large amounts of weight lost at $100^{\circ} \mathrm{C}$, which was observed in TGA, to the loss of adsorbed and some combined water in the N-A-S-H gel, which resembles weight loss of $\mathrm{C}-\mathrm{S}-\mathrm{H}$ in Portland cement cases. Nevertheless, although nanosized crystalline formation and zeolites have been found as secondary products

1 "Zeolite water" is also another term frequently used by researchers. It mainly comprises of weakly bound water (free water) and metal-bound water, in which the metal-bound water co-ordinates with adsorbed metal ions, and hence, zeolite water is mainly adsorbed water and a change in the conditions of the zeolite can lead to its desorption (White et al., 2010). in geopolymers (Bakharev, 2006; Oh, Moon, Mancio, Clark, \& Monteiro, 2011), their quantities are not substantial. Duxson (2006) and Fernández-Jiménez et al. (2007) concluded that the majority of the water in geopolymers is in the form of free water, with the remaining "likely to be present as tightly bound water or hydroxyl groups on the surface of the gel."

Davidovits (2012), however, has clearly pointed out that a geopolymer is not a hydrate and the term N-A$\mathrm{S}-\mathrm{H}$ is not correct to define a Na geopolymer. Moreover, he called for an effort to be made to stop giving "bad" definition to geopolymers with non-proven facts. It is thus evident that the key argument relies on whether there is structural water in the geopolymeric product. It is known that, the main product of most Portland cement, C-S-H (calcium silicate hydrate) crumbles at $600^{\circ} \mathrm{C}$, which leads to most of the Portland cement's failure and spalling (Neville, 2011). The authors agree with Duxson, Lukey, and van Deventer (2007) that it serves no scientific purpose to argue whether the other names for geopolymers, such as low-temperature aluminosilicate glass and inorganic polymer concrete, are correct. However, it is important to know whether $\mathrm{N}-\mathrm{A}-\mathrm{S}-\mathrm{H}$ or sodium aluminosilicate gel stands for a hydrate. This is important because this knowledge would actually inform whether geopolymers have predominant structural water and the nature of this water, which is vital for explaining its good fire-resistance property compared to Portland cement concrete.

Therefore, the main focus in this research is to explore whether the geopolymer product is a hydrate (N-A-S-H or C-A-S-H). Fly ash-based geopolymers activated by $\mathrm{Na}_{2} \mathrm{CO}_{3}$ and $\mathrm{Ca}(\mathrm{OH})_{2}$, treated under various temperatures, were synthesised, and IR was used as the main technique to investigate the role of water/hydroxyls in geopolymers.

\section{EXPERIMENTAL PROGRAMME}

\subsection{Synthesis of geopolymers}

F-fly ash was used as the raw material for producing geopolymers, and the combination of $\mathrm{Na}_{2} \mathrm{CO}_{3}$ and $\mathrm{Ca}(\mathrm{OH})_{2}$ was used as the activator. These are less conventional activators, and their use results in producing $\mathrm{NaOH}$ and $\mathrm{CaCO}_{3}$. The main components of F-fly ash used in this research are $\mathrm{SiO}_{2}$ and $\mathrm{Al}_{2} \mathrm{O}_{3}$ whose contents were 63.46 and $26.71 \%$, respectively (De Weerdt et al., 2011). The basic mix comprised $\mathrm{Ca}(\mathrm{OH})_{2}, \mathrm{Na}_{2} \mathrm{CO}_{3}$, and fly ash, with a mass ratio of 1:0.24:5. The solids to water ratio was 1.66.

An environmental room (denoted as ER) was used for maintaining uniform curing conditions of $23^{\circ} \mathrm{C}$ and $58 \%$ relative humidity. The mixture was stirred for 15 min using an electrical mixer, and the paste was cast in polyethylene vials with dimensions: $55 \mathrm{~mm}$ in 
length and $16 \mathrm{~mm}$ in diameter. Each of the vials had an air-tight cover. All the vials were sealed in a plastic bag and placed in the environmental room for 7 days (this stage is denoted as $7-E R$ ). At the age of 7 days, the samples were stripped out of the plastic vials and placed in an oven at $105^{\circ} \mathrm{C}$ for $24 \mathrm{~h}$ (this stage is denoted as G-105) for further curing. Finally, they were placed in a muffle furnace at $1050^{\circ} \mathrm{C}$ for $48 \mathrm{~h}$ (this stage is denoted as G-1050) for calcination. The micro-structure investigation includes the necessity to stop the reaction at each stage where the certain samples reach their final intended terminal (as detailed below), crushing specimens into powdery form, and then taking samples using the quartering method. Later, the samples were investigated using ATR-IR.

\subsection{Reaction-stopping procedures}

Acommonly used method for stopping further reactions of a geopolymer sample in a particular stage is to immerse the sample in a solvent exchanging agent for a specific period of time and then dry it at $40-60^{\circ} \mathrm{C}$. In this research, two methods for stopping reactions of samples 7-ER from proceeding further were adopted. In method 1, immediately after 7 days' curing (denoted as 7-ER), a sample is placed directly in a desiccator connected to a constantly operating vacuum pump until the sample is sent for infrared spectroscopy (IR) examination. In method 2, selected samples were immersed in $95 \%$ ethanol for $1 \mathrm{~h}$, the solution was then filtered, and the residue was placed in an oven at $40^{\circ} \mathrm{C}$ until its weight became constant (denoted as 7-ER-E). Samples 7-ER and 7-ER-E were then placed in the oven at $100^{\circ} \mathrm{C}$ for $30 \mathrm{~min}$ (denoted as 7-ERD and 7-ER-ED, respectively). Infrared spectroscopy was applied on samples treated by both methods and thus allowed examining differences in microstructure that may have occurred as a result of applying either method.

\subsection{Attenuated total reflectance-infrared spectroscopy (ATR-IR) test conditions}

IR has been widely used for identification of compounds and microstructure analysis in both cement reactant products and geopolymers, especially with respect to functional groups of oxygen-hydrogen and Si-O-T (Si and $\mathrm{Al}$ ). The common XRD technique including quantification, however, is limited to analysing the microstructure of crystalline phases and quantifying the amorphous phase. Therefore, ATR-IR technique is used in this research to further investigate the produced disordered amorphous product. ATR-IR tests were conducted using PerkinElmer Spectrum 100 FTIR equipped with the universal ATR accessory of a diamond/Zn Se crystal. Spectra were measured from 4000 to $650 \mathrm{~cm}^{-1}$ with a $4-\mathrm{cm}^{-1}$ resolution, single bounce, and total of 32 scans.

\section{RESULTS AND DISCUSSION}

The results obtained using XRD in previous research (Fang \& Kayali, 2013) showed that the majority of the synthesized geopolymers are mainly amorphous, especially the sodium contained complex. The residual calcium, on the other hand, exists in the form of calcite, portlandite, and gypsum. After $48 \mathrm{~h}$ of calcination at $1050^{\circ} \mathrm{C}$, the amorphous $\mathrm{Na}$ complex reappeared as albite and labradorite. The common XRD technique including quantification, however, is limited to analysing the microstructure of crystalline phases and quantifying the amorphous phase. Therefore, ATR-IR technique is used to further investigate the produced disordered gel.

The IR technique has been successfully adopted to identify compounds and structures including both amorphous and crystalline phases of Portland cement since 1960s (Fernandez-Carrasco et al., 2012). It has also been widely used for studying geoploymers in an effort to investigate the formation of $\mathrm{N}-\mathrm{A}-\mathrm{S}-\mathrm{H}$ and $\mathrm{C}-\mathrm{A}-\mathrm{S}-\mathrm{H}$, which, in some cases, were considered to be the geopolymerization products (Garcia-Lodeiro, Palomo, Fernández-Jiménez, \& Macphee, 2011). In general, stretching and bending are the two forms of molecular vibrations present in IR spectra. The former involves changes in the bond length, stretch in-phase (symmetrical stretching) or out-phase (asymmetric stretching), and the latter involves changes in the bond angle (FernandezCarrasco et al., 2012).

In the following subsections 3.1 and 3.2 , IR was employed to first examine the development of geopolymers' main backbone structure, whether a matured Si-O-T ( $\mathrm{T}=\mathrm{Si}$ or $\mathrm{Al}$ )-based network has been formed. Then, IR was used to further explore the changes of oxygen-hydrogen bond at different stages. In addition, the comparison between geopolymers and main cement hydration products is discussed in the light of IR analysis. The data analysis and discussion are meant to be thorough and open to further discussion, follow-up research, and potential repeatability.

\section{1 $\mathrm{Si}-\mathrm{O}-\mathrm{T}(\mathrm{T}=\mathrm{Si}$ or $\mathrm{Al})$ evolution at various stages of geopolymerization}

The IR spectra of geopolymers at various stages are shown in Figure 1. The principal absorption band at $1050.9 \mathrm{~cm}^{-1}$ in the fly ash is a combination of the vibrations of asymmetric $\mathrm{Si}-\mathrm{O}-\mathrm{Si}$ stretching of amorphous silica and $\mathrm{Si}-\mathrm{O}-\mathrm{Al}$ networks relating to amorphous aluminosilicate (Padmaja, Anilkumar, Mukundan, Aruldhas, \& Warrier, 2001). A strong peak in this region (950-1250 $\left.\mathrm{cm}^{-1}\right)$ is typical of the glassy phase in fly ash (Lee \& Van Deventer, 2003), which is the main provider of $\mathrm{Si}$ and $\mathrm{Al}$ sources for the later formation of geopolymers. The peaks at 793.5 and 
$690 \mathrm{~cm}^{-1}$ are associated with four coordinated $\mathrm{Al}-\mathrm{O}$ stretching vibrations and $\mathrm{Si}-\mathrm{O}$ symmetrically stretching vibrations, respectively, attributed to mullite in the fly ash. The peak which appears at $776 \mathrm{~cm}^{-1}$, on the other hand, is frequently found in natural quartz (Davidovits, 2008; Murray \& Gualtieri, 1989). After 7 days of curing, the spectrum of fly ash has completely changed showing several different bands, indicating that the addition of activators have changed the structure of fly ash and formed a new product. The first noticeable change is its broad peak at $1050.9 \mathrm{~cm}^{-1}$, which has disappeared and shifted to $950 \mathrm{~cm}^{-1}$ as a relatively sharp peak in 7-ER and to $954.5 \mathrm{~cm}^{-1}$ in G-105. The shifting of the band at this interval is attributed to $\mathrm{Si}-\mathrm{O}-\mathrm{T}$ asymmetric stretching vibrations. Its position and intensity changes carry vital information on the geopolymer development, especially the incorporation of $\mathrm{Al}$, an observation which has also been reported by several researchers (Padmaja, Anilkumar, Mukundan, Aruldhas, \& Warrier, 2001; Rees, Provis, Lukey, \& van Deventer, 2007).

As the bond length of $\mathrm{Al}-\mathrm{O}$ is longer than that of $\mathrm{Si}-\mathrm{O}$, a smaller bonding force is initially required when more $\mathrm{Al}$ substitutes for $\mathrm{Si}^{4+}$ in the networks, leading to a reduction in the $\mathrm{T}-\mathrm{O}-\mathrm{T}$ bond angle and, correspondingly, the $\mathrm{Si}-\mathrm{O}-\mathrm{T}$ bond shifts to a lower frequency. As Al participation slows down, a higher degree of silica participation continues under hydrothermal conditions, resulting in more cross-linkages and an increment in the T-O-T bond angle and hence, a back shift to a higher frequency in the IR spectra was observed. This phenomenon (shifting to a lower frequency and then to a slightly higher frequency) demonstrates a higher degree of geopolymerization, which is an important characteristic contributing to the increase in mechanical strength (Criado, M., Fernández-Jiménez, A., \& Palomo, A. 2010; Fernández-Jiménez, Pastor, Martin, \& Palomo, 2010). This vibration band, which has its maximum absorbance point depicted in the region $900-1200 \mathrm{~cm}^{-1}$, varies with different Si to Al ratios and $\mathrm{Ca}$ content in the geopolymers. It was found that this band appears at a lower frequency at around 950$960 \mathrm{~cm}^{-1}$ in a pure synthetic aluminosilicate gel system with a high $\mathrm{Ca}$ content $\left(\mathrm{CaO}\right.$ to $\mathrm{SiO}_{2}$ ratio of 3.2 and $\mathrm{SiO}_{2}$ to $\mathrm{Al}_{2} \mathrm{O}_{3}$ ratio of 2), in which its main precipitation is $\mathrm{C}-\mathrm{A}-\mathrm{S}-\mathrm{H}$, including $\mathrm{C}-\mathrm{S}-\mathrm{H}$, whereas in those synthetic gels with low $\mathrm{Ca}$ contents $\left(\mathrm{CaO}\right.$ to $\mathrm{SiO}_{2}$ ratio of 0.24 and $\mathrm{SiO}_{2}$ to $\mathrm{Al}_{2} \mathrm{O}_{3}$ ratio of 3 ), the aforementioned band has been observed in the higher frequency of 1020 $1065 \mathrm{~cm}^{-1}$, in which the main precipitation is from N-AS-H (Garcia-Lodeiro, Palomo, Fernández-Jiménez, \& Macphee, 2011).

According to this observation, the amorphous gel in 7-ER and G-105 is more likely to be calcium aluminosilicate gel instead of sodium aluminosilicate gel and instead of C-S-H. However, this observation of the ternary system is based on pure synthetic gels using sol-gel method, and it may not represent the actual geopolymeric product. As a matter of fact, it was reported that in successful $\mathrm{Na}$ geopolymers with proven rigidity in water, $950-995 \mathrm{~cm}^{-1}$ is the shift range of the Si-O-T band. In addition, this range is largely dependent on the silica content in the activators (Rees, Provis, Lukey, \& van Deventer, 2007).

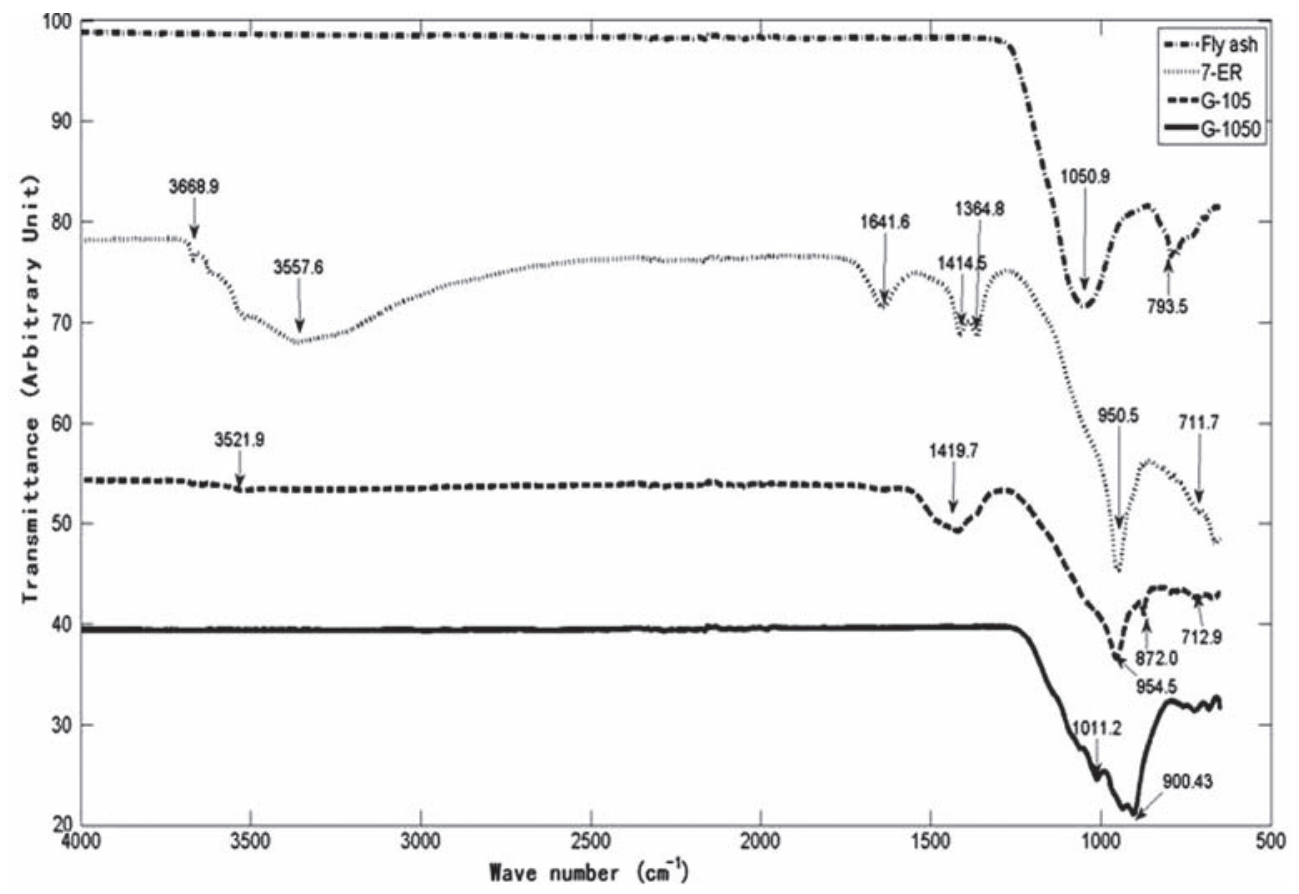

Figure 1. IR spectra of geopolymers at various stages. 
In fact, the possibility of finding $\mathrm{C}-\mathrm{S}-\mathrm{H}$ in the geopolymers synthesized in this research is little. This is supported by the fact that G-1050 maintained its structural integrity instead of spalling and that igneous-rock minerals were formed after extremely high temperatures. This bears similarities with most of Na geopolymers upon heating. Although the existence of C-S-H has been found together with geopolymer gel in the metakaolin and blast furnace slag systems (Yip, Lukey, Provis, \& van Deventer, 2008; Yip, Lukey, \& Van Deventer, 2005), those geopolymers were not subjected to extreme temperatures. Furthermore, if $\mathrm{C}-\mathrm{S}-\mathrm{H}$ is present in $\mathrm{G}-105$, the structural water would also have a strong $\mathrm{O}-\mathrm{H}$ stretching band at $3360 \mathrm{~cm}^{-1}$ and a deformation band at $1641.6 \mathrm{~cm}^{-1}$. Yet both of these bands were nearly absent. So questions such as: is there any evidence suggesting the existence of $\mathrm{N}-\mathrm{A}-\mathrm{S}-\mathrm{H}$, and what are the peaks related to water and hydroxyl groups do arise. These questions will be discussed at length in the subsection below.

\subsection{OH environments at various stages of geopolymerization}

The IR spectra of the geopolymers at various stages are given in Figure 2. Peaks at $3357 \mathrm{~cm}^{-1}$ in 7-ER spectrum and $3360 \mathrm{~cm}^{-1}$ in 7-ER-E spectrum are related to the $\mathrm{O}-\mathrm{H}$ stretching band in water. This vibration band is observed as a very strong peak in the spectrum of distilled water at $3315 \mathrm{~cm}^{-1}$, the intensity and range of which is much stronger and wider than those in 7-ER and 7-ER-E. Peaks at $1641 \mathrm{~cm}^{-1}$ in 7 -ER spectrum and $1642 \mathrm{~cm}^{-1}$ in 7-ER-E spectrum are associated with the $\mathrm{O}-\mathrm{H}$ deformation band, which gives a sharp medium-range peak at $1637 \mathrm{~cm}^{-1}$ in the spectrum of water. The shoulder at $1042 \mathrm{~cm}^{-1}$ in
7-ER-E is the C-C-O stretching band due to ethanol residue. In addition, compared with the IR spectrum of 7-ER-E, the intensity of those bands related to water seems to be stronger in 7-ER. Other than that, the IR spectra of 7-ER and 7-ER-E are similar. In terms of IR, ethanol-quenched sample seems to be drier than the sample placed in the oven, but leaves ethanol residue inside the sample.

Besides the aforementioned two regions, structural water has an additional infrared active region in the wavelength range $600-300 \mathrm{~cm}^{-1}$, which is out of range for this mid-IR equipment (George, 2001). Therefore, it is not completely certain whether the $\mathrm{OH}$ vibration band of water detected in the 7-ER samples is composed entirely of free moisture or contains a certain amount of structural water. However, the signals at 3357 and $1642 \mathrm{~cm}^{-1}$ in G-105 are not clearly resolved and are almost absent. This suggests that even if water is trapped within the lattice of geopolymers, it can only be a small amount, which may interact with the metal ions $\left(\mathrm{Al}^{3+}\right.$ and $\left.\mathrm{Na}^{+}\right)$.

The peaks at $3669 \mathrm{~cm}^{-1}$ in 7-ER-E and $3668 \mathrm{~cm}^{-1}$ in 7 -ER are ascribed to terminal $\mathrm{OH}$ species in which hydrogen bonding could be partially involved, while the peak at $3521 \mathrm{~cm}^{-1}$ in G-105 is the stretching mode of intermolecular hydrogen-bonded $\mathrm{OH}$ groups (George, 2001). This information suggests that there is a certain amount of terminal $\mathrm{OH}$ species forming $\mathrm{H}-\mathrm{O}-$ dimmers or polymer. Hydroxyl species, which originate from alkalies and water, are more likely to attach to the surface of produced gel as terminal $\mathrm{OH}$ species and in covalent bond with $\mathrm{Al}$ atoms.

It is known that cement products, such as C-S-H, tobermorite, and jennite, have several peaks present in

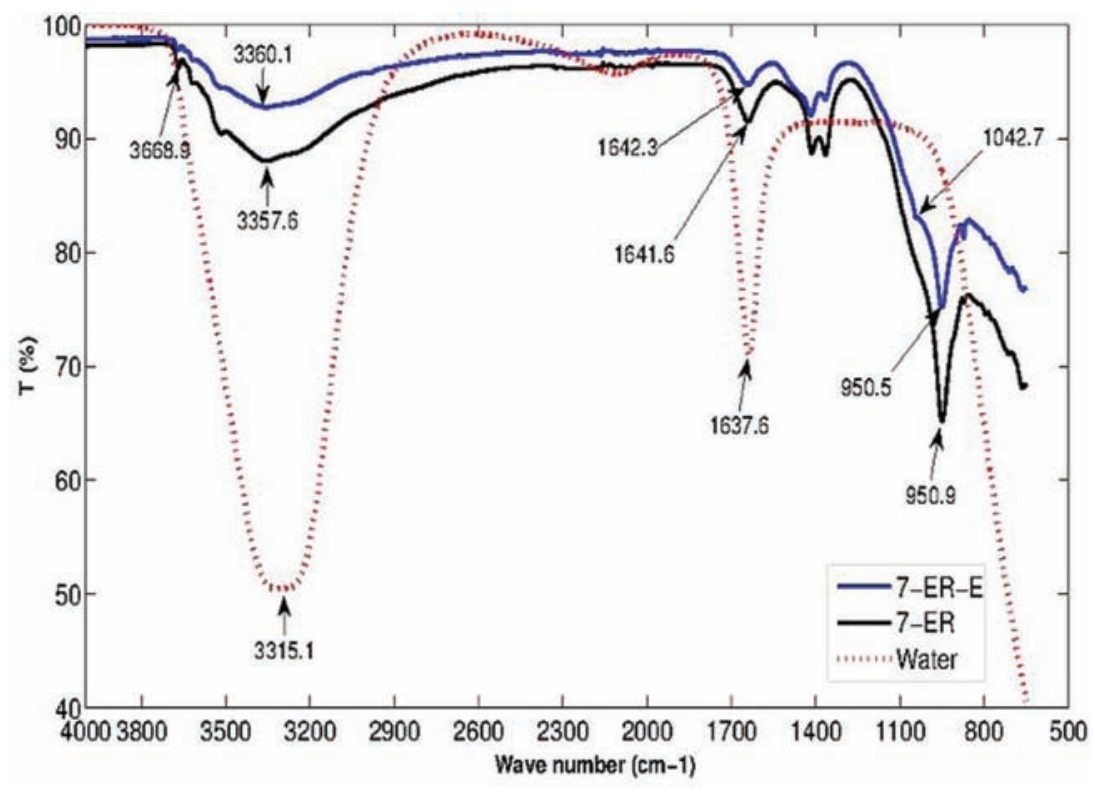

Figure 2. IR spectra of 7-ER, 7-ER-E, and water. 
the OH stretching region $\left(2800-3750 \mathrm{~cm}^{-1}\right)$ in the midIR spectra. This reveals important information on the $\mathrm{OH}$ environments and hydrogen bonding, especially in relation with $\mathrm{Ca}$ and $\mathrm{Si}$ ions. On a closer look at Figure 2, there seems to be some small shoulder peaks around $3500-3700 \mathrm{~cm}^{-1}$ region in 7-ER and7-ER-E sample, and are less obvious in G-105 sample. Despite the ambiguity about the existence of structural water in geopolymers, it is more likely that the sodium ions tend to interact with the water residing in the pores (Rowles, Hanna, Pike, Smith, \& O'Connor, 2007). Therefore, if 7-ER and 7-ER-E are heated for a short period of time, e.g., heated at $100^{\circ} \mathrm{C}$ for $30 \mathrm{~min}$, changes of $\mathrm{OH}$ stretching vibrations relating to sodium or calcium ions in the pore solution or even in the C-A-S-H, if it exists, can be observed. In addition, these changes can be differentiated from bands attributable to a developed framework in G-105, which is made from heating 7 -ER sample at $105^{\circ} \mathrm{C}$ for $24 \mathrm{~h}$.

The small shoulders, which are centered at 3675 and $3669 \mathrm{~cm}^{-1}$ have the strongest intensities in $7-E R$. The intensity decreases in the order of 7-ER$E$ and 7-ERD, and is nearly absent in G-105 and 7-ER-ED. This means that both heat and ethanol affect the appearance of the regions and intensity of these $\mathrm{OH}$ stretching vibrations, and, evidently heat has greater ability of eliminating these $\mathrm{OH}$ groups because these two peaks are still evident in 7-ER$E$ but much weaker in 7-ERD. Further, the fact that $\mathrm{Al}$... O-H stretching has also been observed in the same region (Kubicki, Sykes, \& Rossman, 1993) suggests that these vibrations are probably contributed to hydrogen bond of $\mathrm{Al}-\mathrm{OH}$ and sodium ions that are in the pore solution. These two peaks are unlikely to be $\mathrm{Ca}-\mathrm{OH}$ correlated [the $\mathrm{OH}$ groups in $\mathrm{Ca}(\mathrm{OH})_{2}$ are not considered to be hydrogen bonded], as cement product, such as tobermorite, calcium aluminosilicate, and jennite, seem to have $\mathrm{OH}$ stretching band in a lower region (3624-3100 cm1) (Yu, Kirkpatrick, Poe, McMillan, \& Cong, 1999). In addition, jennite has several distinctive narrow $\mathrm{OH}$ bands in this region with well-defined hydrogen bond distance (around 3.10-2.83 $\AA$ ). It also has a broad band centered at $3140 \mathrm{~cm}^{-1}$ due to the interlayer and surface adsorbed water (Yu, Kirkpatrick, Poe, McMillan, \& Cong, 1999).

On the other hand, the similar intensity decreasing order observed at 3623 and $3520 \mathrm{~cm}^{-1}$ is more likely to be $\mathrm{Ca}-\mathrm{OH}$ correlated as it is also observed in jennite (Yu et al., 1999). It has a smaller $\mathrm{O}-\mathrm{H} \ldots \mathrm{O}$ distance $(3.137 \AA)$ than that in sodium-correlated $\mathrm{OH}$ stretching, attributed to the substitutions of cation that is bonded to an $\mathrm{OH}$ group, which can cause a shift in the frequency by a magnitude of $100 \mathrm{~cm}^{-1}$ in aluminosilicates (Kubicki, Sykes, \& Rossman, 1993). The aforementioned regions are probably a result of the hydrogen bonds in the structures, such as
$\mathrm{Na}^{+}(\mathrm{OH})_{2} \mathrm{Al}-\mathrm{O}-\mathrm{Si}$, in geopolymers' pore solution, as they are very weak and nearly absent in samples that are dried using heat, such as 7-ERD, 7-ER-ED, and G-105. When the geopolymers have sufficient pore solution or accessible hydroxyl groups, some $\mathrm{Na}$ and $\mathrm{Ca}$ cations in the cavities tend to associate with $\mathrm{Al}$ anions as a charge compensator and get to be surface bound to the matrix, in the form of $\mathrm{M}^{n+}-\mathrm{Al}^{-}-(\mathrm{OH})_{3}\left(\mathrm{M}^{n+}\right.$ stands for cations with $n$ number of positive charges) (Bouyer, Geneste, Ispas, Kob, \& Ganster, 2010; Rowles, Hanna, Pike, Smith, \& O'Connor, 2007). On the other hand, some of these cations tend to associate with the non-bridging oxygen of the framework's siliceous part and form $\mathrm{Si}-\mathrm{O}^{-} \ldots \mathrm{M}^{n+}$, in which they act as the network modifier and become incorporated in the matrix. In this situation, the monovalent cations fully meet the requirement, which is balancing the negative monovalent charge ${ }^{2}$ of $\mathrm{Al}$, while divalent ions, such as $\mathrm{Ca}^{2+}$, meet it only partially. This could also explain the fact that Ca-containing minerals appeared in 7-ER and G-105, but were absent in any $\mathrm{Na}$-containing minerals. This is because in terms of the ability of getting incorporated in the geopolymer matrix, Ca cations are weaker competitors than $\mathrm{Na}$ cations (Fang \& Kayali, 2013). When the pore solution is reduced, such as in the case of G-105, the cations that are surface bound tend to associate with the siliceous part of the framework. Also, the small absorption band at $3643 \mathrm{~cm}^{-1}$ in G-105, which is nearly absent in the other samples, suggests its association with $\mathrm{Si}-\mathrm{OH}$ and is indicative of a more developed network.

When heat is applied to geopolymers during curing stages, moderate temperatures are adopted $\left(40-80^{\circ} \mathrm{C}\right)$, and part of the adsorbed water is still retained; thus, some researchers have characterized the structure of a geopolymer as N-A-S-H (Yu et al., 1999). However, when the temperature exceeds a certain threshold, the water that appears to be incorporated in the structure escapes and leaves little structural water in the matrix. This may explain the phenomenon that sample G-1050 maintains its shape when the temperature reaches $1500^{\circ} \mathrm{C}$ instead of spalling such as most ordinary hardened Portland cement paste. The threshold of the temperature needs to be further investigated using TGA-DSC, which will be explored in further research.

2 The statement that $\mathrm{Al}$ bears a negative charge is used in a particular structure - sialate (silicon-oxo-aluminate). A sialate consists of $\mathrm{SiO}_{4}$ and $\mathrm{AlO}_{4}$ linked alternately by sharing all oxygen atoms. In order to satisfy the octet rule, in this particular structure unit, $\mathrm{Si}$ can be either an electron donator or a receiver while oxygen an electron receiver, and thus, $\mathrm{Al}$ is an electron donator in acidic medium and receptor in alkaline medium (Davidovits, 2008). Therefore, the notion of "negative Al" or "negatively charged Al" is often used in the geopolymer terminology. 


\section{CONCLUSIONS}

1. This research has explored the role of water and micro-structure of class $\mathrm{F}$ fly ash-based geopolymers activated by $\mathrm{Na}_{2} \mathrm{CO}_{3}$ and $\mathrm{Ca}(\mathrm{OH})_{2}$. The main backbone structure, the $\mathrm{Si}-\mathrm{O}-\mathrm{T}$ bond, shifted to a higher frequency and later shifted back to a lower frequency in the region $950-960 \mathrm{~cm}^{-1}$, in the mid-IR spectra. This indicated that two different stages are involved in the geopolymerization process: initially, more $\mathrm{Al}$ substitutes for $\mathrm{Si}^{4+}$ in the networks and, later, as Al participation slows down, a higher degree of silica participation continues under hydrothermal conditions, resulting in more cross-linkages. The position of this principal band and other obtained data further suggests that the produced geopolymers do not comprise C-S-H and probably not C-A-S-H.

2. The $\mathrm{OH}$ stretching vibrations, which are not related to free water, exhibit changes in the region 3520 $3675 \mathrm{~cm}^{-1}$. This provides information on the state of cations in geopolymers. The fact that these bands are sensitive to heat $\left(105^{\circ} \mathrm{C}\right)$ and exhibit differences between ethanol-quenched and desiccator vacuum-pumped samples suggests the association of sodium and calcium cations with terminal hydroxyl groups or water that most likely reside in the pores. This indicates that some amounts of the water are adsorbed water and surface bound. Furthermore, some of the metal cations are not able to be incorporated in the three dimensional matrix to coordinate with Al.

3. The evidence obtained from IR is not adequate to prove the existence of structural water, and the assumption that the main product of $\mathrm{Na}$ geopolymer is $\mathrm{N}-\mathrm{A}-\mathrm{S}-\mathrm{H}$ is not favoured. Even if there is structural water, it must be a small amount and is not easy to be detected, as the produced geopolymers still maintained its structural integrity and even gained strength after firing at $1050^{\circ} \mathrm{C}$. If there is structural water in the matrix, the amount must be very small so that its evaporation pathway in the pores would not compromise its mechanical strength.

\section{ACKNOWLEDGMENTS}

The research presented in this paper was conducted during the second author's PhD candidature at the School of Information and Engineering Technology of the University of New South Wales, Canberra. The author is grateful to UNSW for providing the facilities to carry out this research through the Australian higher degree education program. The authors would also like to thank the financial support provided by National Natural Science Foundation of China (No. 51508337).

\section{REFERENCES}

Alonso, S., \& Palomo, A. (2001a). Calorimetric study of alkaline activation of calcium hydroxide metakaolin solid mixtures. Cement and Concrete Research, 31(1), 25-30.

Alonso, S., \& Palomo, A. (2001b). Alkaline activation of metakaolin and calcium hydroxide mixtures: Influence of temperature, activator concentration and solids ratio. Materials Letters, 47(1), 55-62.

Bakharev, T. (2006). Thermal behaviour of geopolymers prepared using class $\mathrm{F}$ fly ash and elevated temperature curing. Cement and Concrete Research, 36(6), 1134-1147.

Bouyer, F., Geneste, G., Ispas, S., Kob, W., \& Ganster, P. (2010). Water solubility in calcium aluminosilicate glasses investigated by first principles techniques. Journal of Solid State Chemistry, 183(12), 2786-2796.

Castaldi, P., Santona, I., Cozza, C., Giuliano, V., Abbruzzese, C., Nastro, V., \& Melis, P. (2005). Thermal spectroscopic studies of zeolite exchanged with metal cations. Journal of Molecular Structure, 734(1), 99-105.

Criado, M., Fernández-Jiménez, A., \& Palomo, A. (2010). Alkali activation of fly ash. Part III: Effect of curing conditions on reaction and its graphical description. Fuel, 89(11), 3185-3192.

Davidovits, J. (2008). Geopolymer chemistry and applications (3rd ed.). Raleigh, NC: Lulu.

Davidovits, J. (2012). State of the Geopolymer R\&D, 2012. Retrieved from: http://www.geopolymer.org/ camp/gpcamp-2012

De Weerdt, K., Haha, M. B., Le Saout, G., Kjellsen, K., Justnes, H., \& Lothenbach, B. (2011). Hydration mechanisms of ternary Portland cements containing limestone powder and fly ash. Cement and Concrete Research, 41(3), 279-291.

Duxson, P. (2006). The structure and thermal evolution of metakaolin geopolymers (Ph.D. thesis). Department of Chemical and Biomolecular Engineering.

Duxson, P., Fernández-Jiménez, A., Provis, J. L., Lukey, G. C., Palomo, A., \& van Deventer, J. S. J. (2007). Geopolymer technology: The current state of the art. Journal of Materials Science, 42(9), 2917-2933.

Duxson, P., Lukey, G. C., \& van Deventer, J. S. J. (2007). Physical evolution of Na-geopolymer derived from metakaolin up to $1000^{\circ} \mathrm{C}$. Journal of Materials Science, 42(9), 3044-3054.

Fang, Y., \& Kayali, O. (2013). The fate of water in fly ash-based geopolymers. Construction and Building Material, 39, 89-94.

Fernandez-Carrasco, L., Torrens-Martin, D., Morales, L., \& Martinez-Ramirez, S. (2012). Infrared spectroscopy in the analysis of building and construction materials. INTECH 3, 69-82. 
Fernández-Jiménez, A., Garcia-Lodeiro, I., \& Palomo, A. (2007). Durability of alkali-activated fly ash cementitious materials. Journal of Materials Science, 42(9), 3055-3065.

Fernández-Jiménez, A., Palomo, A., \& Criado, M. (2005). Microstructure development of alkaliactivated fly ash cement: A descriptive model. Cement and Concrete Research, 35(6), 1204-1209.

Fernández-Jiménez, A., \& Palomo, A. (2005a). Composition and microstructure of al-kali activated fly ash binder: Effect of the activator. Cement and Concrete Research, 35(10), 1984-1992.

Fernández-Jiménez, A., \& Palomo, A. (2005b). Mid-infrared spectroscopic studies of alkaliactivated fly ash structure. Microporous and Mesoporous Materials, 86(1), 207-214.

Fernández-Jiménez, A., \& Palomo, A. (2009). Nanostructure/microstructure of fly ash geopolymers. In J. Provis \& J. van Deventer (Eds.), Geopolymers: Structures, processing, properties and industrial applications (pp. 89-117). Sawston, England: Woodhead Publishing.

Fernández-Jiménez, A., Palomo, A., Pastor, J. Y., \& Martin, A. (2008). New cementitious materials based on alkali-activated fly ash: Performance at high temperatures. Journal of the American Ceramic Society, 91(10), 3308-3314.

Fernández-Jiménez, A., Palomo, A., Sobrados, I., \& Sanz, J. (2006). The role played by the reactive alumina content in the alkaline activation of fly ashes. Microporous and Mesoporous Materials, 91(1), 111-119.

Fernández-Jiménez, A., Pastor, J. Y., Martin, A., \& Palomo, A. (2010). High-temperature resistance in alkali-activated cement. Journal of the American Ceramic Society, 93(10), 3411-3417.

Garcia-Lodeiro, I., Palomo, A., Fernández-Jiménez, A., \& Macphee, D. (2011). Compatibility studies between N-A-S-H and C-A-S-H gels. Study in the ternary diagram $\mathrm{Na}_{2} \mathrm{O}-\mathrm{CaO}-\mathrm{Al}_{2} \mathrm{O}_{3}-\mathrm{SiO}_{2}-\mathrm{H}_{2} \mathrm{O}$. Cement and Concrete Research, 41(9), 923-931.

George, S. (2001). Infrared and raman characteristic group frequencies tables and charts. Chichester, England: Wiley.

Kubicki, J., Sykes, D., \& Rossman, G. (1993). Calculated trends of $\mathrm{OH}$ infrared stretching vibrations with composition and structure in aluminosilicate molecules. Physics and Chemistry of Minerals, 20(6), 425-432.

Lee, W., \& Van Deventer, J. (2003). Use of infrared spectroscopy to study geopolymerization of heterogeneous amorphous aluminosilicates. Langmuir: the ACS Journal of Surfaces and Colloids, 19(21), 8726-8734.

Murray, R. A., \& Gualtieri, J. G. (1989). Fundamental lattice vibrations in quartz. Proceedings of the 43rd IEEE Annual Symposium on Frequency Control, 1989, pp. 477-484.
Nakamura, K., Hatakeyama, T., \& Hatakeyama, H. (1981). Studies on bound water of cellulose by differential scanning calorimetry. Textile Research Journal, 51(9), 607-613.

Neville, A. M. (2011). Properties of concrete (5th ed.). Upper Saddle River, NJ: Prentice Hall.

Oh, J. E., Moon, J., Mancio, M., Clark, S. M., \& Monteiro, P. J. (2011). Bulk modulus of basic sodalite, $\mathrm{Na}_{8}\left[\mathrm{AlSiO}_{4}\right]_{6}(\mathrm{OH})_{2} \cdot 2 \mathrm{H}_{2} \mathrm{O}$, a possible zeolitic precursor in coal-fly-ash-based geopolymers. Cement and Concrete Research, 41(1), 107-112.

Padmaja, P., Anilkumar, G., Mukundan, P., Aruldhas, G., \& Warrier, K. (2001). Characterisation of stoichiometric sol-gel mullite by Fourier transform infrared spectroscopy. International Journal of Inorganic Materials, 3(7), 693-698.

Palomo, A., Fernández-Jiménez, A., Kovalchuk, G., Ordoñez, L., \& Naranjo, M. (2007). Opc-fly ash cementitious systems: Study of gel binders produced during alkaline hydration. Journal of Materials Science, 42(9), 2958-2966.

Rees, C. A., Provis, J. L., Lukey, G. C., \& van Deventer, J. S. (2007). Attenuated total reflectance Fourier transform infrared analysis of fly ash geopolymer gel aging. Langmuir: the ACS Journal of Surfaces and Colloids, 23(15), 8170-8179.

Rowles, M., Hanna, J. V., Pike, K., Smith, M. E., \& O'Connor, B. (2007). ${ }^{29} \mathrm{Si},{ }^{27} \mathrm{Al},{ }^{1} \mathrm{H}$ and ${ }^{23} \mathrm{Na}$ MAS NMR study of the bonding character in aluminosilicate inorganic polymers. Applied Magnetic Resonance, 32(4), 663-689.

Shi, C., Fernández-Jiménez, A., \& Palomo, A. (2011). New cements for the 21st century: The pursuit of an alternative to Portland cement. Cement and Concrete Research, 41(7), 750-763.

White, C. E., Provis, J. L., Proffen, T., \& Van Deventer, J. S. J. (2010). The effects of temperature on the local structure of metakaolin-based geopolymer binder: A neutron pair distribution function investigation. Journal of the American Ceramic Society, 93(10), 3486-3492.

White, C. E., Provis, J. L., Proffen, T., \& Van Deventer, J. S. J. (2011). Evolution of local structure in geopolymer gels: An in situ neutron pair distribution function analysis. Journal of the American Ceramic Society, 94(10), 3532-3539.

Yip, C., Lukey, G., \& Van Deventer, J. (2005). The coexistence of geopolymeric gel and calcium silicate hydrate at the early stage of alkaline activation. Cement and Concrete Research, 35(9), 1688-1697.

Yip, C. K., Lukey, G. C., Provis, J. L., \& van Deventer, J. S. (2008). Effect of calcium silicate sources on geopolymerisation. Cement and Concrete Research, 38(4), 554-564.

Yu, P., Kirkpatrick, R. J., Poe, B., McMillan, P. F., \& Cong, X. (1999). Structure of calcium silicate hydrate (C-S-H): Near-, mid-, and far-infrared spectroscopy. Journal of the American Ceramic Society, 82(3), 742-748. 